Perriton L, Reynolds M, Critical Management Education in Challenging Times, Management Learning (Volume 49, Issue 5), pp. 521-536. Copyright (C) The Authors 2018. Reprinted by permission of SAGE Publications.

\title{
Critical Management Education in Challenging Times.
}

Linda Perriton, University of Stirling

Michael Reynolds, Lancaster University

Abstract

In this article we review the aims of the Critical Management Education project against the background of changes in the student population and increasing institutional pressures to protect sources of income. We revisit the foundations of the critical project in the contributions of radical - including critical management - educators, examine recent changes in the management education context and review the ways our theory and practice has responded and should respond to these changes. We call for the critical management education community to review the basis of its critical work with students if the 'classroom' is to remain an important site for criticality.

Key words: CME; contextual changes; participative pedagogies; difference.

It is now more than a decade since we suggested in this journal that it was time for the development of a new sensibility in critical management education (CME) that considered the conflicted role of the critical educator (Perriton and Reynolds, 2004). In that paper we called for a shift from the idea of the critical management educator 'liberating' students from their

misguided faith in mainstream management solutions using critical theory, towards classroom approaches that challenged the authoritarianism and masculinist tendencies inherent in this pedagogical model. Our observation at the time was that CME in general lacked an effective model of classroom practice that could work with issues of difference, and that it needed to 
engage more with radical education theorists. By differences, we refer to characteristics such as gender, ethnicity, sexuality, age, disability and, in an educational setting, of ways in which people see themselves or are seen by others as 'other'. In either case, difference can and often does, intersect with manifestations of power both in the classroom and in its organizational context (Reynolds and Trehan, 2003). That original challenge regarding classroom practice has become more pressing in the intervening years because of the structural changes that UK higher education has undergone, and as a response to the internationalization of the student cohort. Our observation, nearly 15 years later from the original call for change, is that it is not only the critical content versions of CME e.g. the use of critical theorists in lectures and readings that require rethinking. The critical process versions e.g. where criticality is expressed through classroom practice and educational design, and which have traditionally found a sympathetic audience amongst Management Learning readers, also need to be interrogated.

The globalised management classroom raises difficult questions about what differences are being learnt from, what commonalities are being assumed, and what critical outcomes - if any - are valued by the management education community. Notwithstanding our classroom interventions, imperfectly globalized campuses and university towns and cities also give students a lived experience of difference outside of the classroom; not all those experiences are positive. Given the context of a burgeoning racist and anti-intellectual public sphere that reduces the public space for discussing difference as a social good, we would have expected a critical response from $\mathrm{CME}$ to the changing context of difference. 
The concern of this paper is to ask whether the assumptions embedded in CME's pedagogical practices around difference hinder it from responding to the current context of UK higher education, and where new or adapted forms of pedagogical CME might emerge from and/or thrive. Our paper argues that the macro issues shaping UK higher education bring into question the relevance of our continued assumptions about critical pedagogy, its structure, and processes. Clearly, pedagogy continues to matter to practice. Not least because since the Brexit vote (Fuller, 2017), raising issues of how identity and difference are experienced in the UK seems both difficult and needed. Given the increasing difficulties that pedagogical forms of CME have in finding space in the management curriculum, and the wider political context, it is important to consider whether the type of criticality CME offers is still relevant to its target audience.

In the first section of this paper, we revisit the positions taken by the first wave of critical pedagogues and critical management educators that established its desire to create a critical pedagogy, i.e. educational processes that are 'open' to marginalised individuals, and a commitment to reducing the power of the tutor in educational design decisions ${ }^{1}$. Implicit in this account is the acknowledgement that educational approaches and practices always arise in tension with institutional and social structures (Giroux, 1981). And it is our interest in those tensions that informs the second section that examines the changes in the UK educational landscape since the early 2000s. We note the rapid re-orientation of the postgraduate offerings of Business Schools towards volume and international recruitment, which crowded out smaller, critical programmes. In the final sections, we review whether CME - now in its middle-age - has responded intellectually to the changed context in the 
same way as radical education has. We end by asking the CME practice community to engage in a revised debate about criticality and its possibilities in the business school.

\section{Reprising the Core Concerns of Critical Management Education}

Inequality based on ethnicity, and subsequently gender, was a key driver to the development of radical education approaches in the US. Giroux $(1981,1988)$ and Ellsworth (1989) are recognized as foundational theorists of critical education practice and their ideas, in turn, have informed CME classroom practice. Giroux's concept of a strategy based radical (1981) was an early attempt to define the qualities of an educator who ensured the principles underlying methods and roles in the classroom were as important as curriculum and content in expressing democratic ideals. Giroux drew attention to educators who 'called into question the political and normative underpinnings of traditional classroom pedagogical styles' (1981: 65) and, in a later publication (1983), advocated replacing traditional modes of transmission with classroom relationships in which students are able 'to challenge, engage, and question the form and substance of the learning process' (p. 202).

Group work ${ }^{2}$ was a way that Giroux saw of demystifying the "traditional, manipulative role of the teacher' (1988: 39). His stress on the importance of constructing a critical pedagogy involving methods and social structures as well as content and curriculum, and an associated revision of tutor roles and tutor-student relationships which changed the dynamics of power and control within the classroom would also become characteristics of CME with its emphasis on participative pedagogies based on group work. Group work offered an 
alternative to more hierarchical pedagogies and provided a way of learning about how to take part in democracy. However, the dilemma that Giroux identified was that educators had to express those ideals in a context that undermined the possibilities for doing so.

The emergence of critical management education

In their introduction to a landmark publication Critical Management Studies, Alvesson and Willmott (1992) challenged the position 'of taking the neutrality or virtue of management as self-evident or unproblematical' (p. 1). Drawing on Critical Theory in particular, Alvesson and Willmott's premise was that 'management [was] too potent in its effects upon the lives of employees, consumers and citizens to be guided by a narrow, instrumental form of rationality' (p. 1). In Critical Management Studies, authors from a range of management education disciplines argued for a more critical perspective than they believed to be promoted within business schools at that time. There followed other publications which challenged the function of business and management schools and the curriculum which was available to management students (see for example, Willmott, 1994; Grey and Mitev, 1995). In its most basic form, the term ' $\mathrm{CME}$ ' became - and remains for some educators - shorthand for the substitution of mainstream, normative teaching material with critical theoretical or interpretive texts and other content. However, in the early 1990s, applying critical perspectives to the classroom practice of management education including the roles, values and beliefs of management educators, was part of the overall critical movement. Out of this a theory and practice of process critical CME gathered momentum (see for example French and Grey, 1996; Burgoyne and Reynolds, 1997; Currie and Knights, 2003). 
Difference was core to the critical content being generated, as in the work of Alvesson and Willmott who drew attention to the need to address inequalities of 'class, race or gender' in management and organisations. And, in the early years of CME classroom practice, there was also an awareness of the importance of difference, although it tended to focus on the need to engage with power differences than those that arose from ethnicity, gender, sexual identity, or disabilities. Grey, Knights and Willmott (1996), reflected a Giroux-like concern with power relations but worried about power's ability to block the possibility of a democratic educational space, as 'being placed in the role of teacher mitigates against the possibility of entirely suspending authoritarian relations' (p.107). French and Grey (1996) noted that the feminist presence in education literature (e.g. Luke and Gore, 1992) - which in many ways would have reflected the Freirean practice of the validation of personal experience, activism, critical thinking, and participatory learning via classroom dialogue - was absent from the management education literature. Sinclair, (1997) working out of an educational/feminist and Freirean discourse to highlight differences in women's preferred ways of learning, observed that 'management education takes place within a much more circumscribed context where what constitutes management knowledge has been well established and rarely problematized' (p.316).

Through these varied feminist influences, a process version of CME slowly developed albeit not uniformly or completely - that put difference and power centre-stage. Reflecting these concerns, CME process practitioners are likely to emphasise criticality in methods and relationships as much as in subject content, with an associated revision of tutor roles and 
tutor-student relationships, changing the dynamics of power and control in the course and classroom. Consequently, the critical pedagogies that emerged tend to favour participative approaches, whether in the classroom (Dehler et al 2001; Fenwick, 2005), in 'learning communities' - particularly in online courses (Hodgson and Waitland, 2004) or - as in the development of 'critical action learning', in management development programmes (Reynolds and Vince, 2004; Rigg and Trehan, 2004). These designs often involve working in groups, whether in projects or in experiential activities both indoors and outdoors, providing students with opportunities to learn about working relationships and the dynamics of power and difference which develop within them. Group work is therefore likely to be a key component of CME and associated pedagogies.

In this section, we have traced the origins of CME in the radical education tradition and shown that its early forms were similarly interested in power differentials. Whether the focus on the educator and not the educated in this early period was misplaced, or simply characteristic of the wider CMS movement as a whole, CME has - albeit slowly - developed a broader view of power as also being expressed through ethnic, gender, sexual orientation, disability, and wealth differentials. However, the changed context of critical management education creates significant challenges as to how critical management education is framed and practiced in the contemporary business school. It has become necessary to ask what opportunities remain to practice critically in the management classroom and what our practice is now shaped by in terms of institutional change. It is to these changes that we turn in the section which follows. 


\section{The Changed Context of Critical Management Education}

In the previous section of the paper we highlighted that, in the early incarnation of CME practice, power in the university was identified mainly in the form of its unequal expression between tutor and student. This is unsurprising given that the tenets of critical classroom practice that CME inherited from radical education assumed an intranational context in which ethnicity and gender was placed. However, UK management education now operates within an international context that has altered the possibilities for critical pedagogies focused on difference. In this section, we look at the major drivers behind the altered circumstances of practice around critical forms of learning designs - these are related to fees, internationalisation, and risk reduction. We then consider whether or not the understanding of personal difference has also shifted since CME became established.

Fees

By the early twenty-first century, most western industrialized states had moved towards the use of market solutions to allocate resources to public services, including higher education. For many, the introduction of 'full' undergraduate tuition fees in 2012 that followed a sixyear period of 'top up' fees marked the final stages of the marketization of UK higher education. ${ }^{3}$ Despite some regional differences, i.e. no tuition fees for Scottish undergraduates studying in Scottish universities, and the capping of fees for Welsh undergraduates, neoliberal economic approaches to education are the new 'normal'. Human capital theory has 
normalised the presentation of higher education as an individual rather than a public good (Baptiste, 2001; Nafukho, Hairston, and Brooks, 2004; Ployhart and Moliterno, 2011). Any additional funding, e.g. for research, is also expected to make a return to the national wealth by generating knowledge that can be converted into economic goods. Where such goods cannot be generated, a degree is expected to produce high-skilled entrants to the labour market instead.

Fees have, of course, been the norm in postgraduate management education since postgraduate management degrees were first offered in the early 1960s. The marketization of postgraduate management education is the result of the internationalisation of the cohort and the ability to charge premium fees to the increasing number of students studying outside their country of citizenship (Starkey and Tiratsoo, 2007), especially the high number of students from China choosing to undertake management studies (Crawford and Wang, 2015). The global education market has expanded fourfold since the 1950s from a base of 0.8 million, through the 1990s when there were approximately one million international students, to the present day where it is estimated there are three million students studying abroad. By the 1990s the market was worth approximately US\$27 billion, triggering regulation changes from governments to allow institutions to charge differential fees to international students (Mazzarol and Souter, 2012). The MBA has been the key vehicle for gaining higher fee income from international students by business schools. But most other management degrees have seen large increases in student numbers in all management specialisms, especially those that target students with no work experience who have been priced out of the MBA market (Starkey and Tiratsoo, 2007). 


\section{Internationalisation}

The internationalisation of UK management education, and the pedagogical challenges that have arisen as a result in business schools, has been of increasing interest to educational researchers across the critical and mainstream spectrum (e.g. Crawford and Wang, 2015; Crose, 2011; Mangan et al, 2016; Turner, 2009). Research has been undertaken into the relative underperformance of international students compared to UK and EU students on the same programmes (Crawford and Wang, 2015), and into the effect of a single dominant block of international students on pedagogy (Mangan et al, 2016). The latter research notes that the increase in international student numbers, especially where they outnumber UK students on programmes, can - at its most extreme - evoke a sense of crisis amongst international students (who feel culturally isolated), UK students (who complain that international students do not contribute in class), and staff (who find their former teaching methods are no longer effective). There is a paucity of research around internationalisation and critical pedagogy. Choo's (2007) study is one of the few to examine how international students respond to critical content and/or pedagogy and/or the experience of critical educators in teaching international students. A lack of empirical evidence should not, in Choo's estimation, equate with the assumption of approval. Master of Business Administration (MBA) students were dissatisfied with non-technical content in courses they saw as being critical to their employability (Choo 2007). Chinese MBA students also reported unease in negotiating the dynamics of group work and in the raising of issues related to difference and diversity (e.g. Currie, 2007; Gabriel and Griffiths, 2008). 
As mentioned in the section introduction, the practices of critical education that CME inherited around issues of difference and power assumed an intranational starting point, ethnicity and gender identity was expressed within a common national context. Although the cultural experiences and socio-economic status of students varied, a shared vocabulary - if not access to, and full enjoyment of - a common culture and socio-economic and political environment formed the basis of intra-classroom communication. However, management education is now delivered in an international context that moves large numbers of students and staff around the globe. In the UK, for instance, it is not uncommon for international students to form most of the postgraduate degree cohort and, in some subject areas, for 'home' students to be absent entirely from the student group. Differences experienced by individual students, are formed, understood, and will be played out subsequently in social and national contexts that are remote from those in which the classroom is situated, and are difficult for tutors to understand and negotiate. If we continue to hold that CME should engage with difference as part of its commitment to social justice and critically informed outcomes, then the demographics of the cohort both matter and represent a significant challenge to our practice.

\section{Reduction in Risk Taking}

The emphasis on employability, and the effects of internationalisation, are both forces for conservatism rather than innovation and risk-taking by educators (Naidoo and Jamieson, 2005). One visible effect of the reduction of financial and pedagogical risk-taking has been 
the homogenisation of management education. Management degree programmes gain legitimacy through their ability to attract large international student numbers but are easily replicated by competitor institutions. The period since 2000 has also witnessed the collapse of the binary divide in UK higher education (HE), with institutions that were previously focused on postgraduate studies also seeing the financial logic of offering undergraduate degrees, and vice versa. As a result, both the type of management programme offered - and patterns of provision - have converged (Wilkins and Huisman, 2012).

The standardisation of the postgraduate management 'product' to appeal to an international market has had the effect of crowding out programmes that appeal to social solidarity, aesthetic gratification, and intellectual accomplishment that has traditionally formed critical practice in higher education (Gross and Hogler, 2005). Pedagogical practices are 'disciplined' within universities (Sinclair, 2007: 470), and Bridgman (2007) provides an account of how university authorities put pressure on individual academics for fear of jeopardising external funding from business. Bridgman found his review of relevant literature resulted in a 'highly pessimistic' picture about professionalization and commodification, and a growing ethos which appeared to devalue academic freedom (p. 428). Illustrating Bridgman's point about concern about external sources of income, Gustavs and Clegg (2005) describe a management development pedagogy that was offered as part of executive education based on negotiating what counts as knowledge with participants. The programme came to grief because of opposition both from within the university and from the client organization, 'foundering on the usual reefs of profit, pride and politics' (p. 28). 
The differential fees effect on the market has also resulted in programmes that recruited smaller numbers, or traditionally attracted part-time post-experience UK domiciled students, largely disappearing from the management education offering. In many cases these discontinued programmes were the ones dedicated to fostering critical management education approaches and used group work to explore issues of difference and diversity and democracy (for an account of the UK programmes closed or revised see Sambrook and Willmott, 2014; Tosey and Marshall, 2017). The removal of the smaller, post-experience and part-time programmes that catered to training and development, organisational development, and human resource development practitioners has been especially damaging to critical management education practice around difference. Where there is attention paid to difference in internationalised programmes, it tends to be expressed in terms of cross-cultural management, with the emphasis on 'doing business' in other cultures as opposed to exploring difference through dialogue in groups (Perriton and Elliott, 2017). Where it is still possible to focus on difference, it is to find that difference itself has also shifted conceptually in the period since the foundation of CME, and that it has become enmeshed with identity politics.

\section{Identity Politics rather than Diversity and Equality}

Identity politics, in its current form, references new social movements that have expanded past earlier manifestations of 'pressure groups' or 'interest groups' and that challenge white male hegemony (Walters, 2017). Identity politics includes, but moves beyond consciousness raising, to a place where we can talk about 'women, queers, religious minorities, and racial 
minorities...[and reference issues] that are seen as having particular resonance or importance to these groups: reproductive rights, police violence, trans access and rights etc' (Walters, 2017 unpaginated; Whittier, 2017). Collective identity - how it is seen, and how members want it to be viewed - is the 'identity' to which identity politics in action is traditionally concerned and making collective identity visible is at the core of its activism (Whittier, 2017).

Academic explanations for the rise of identity politics, and its positioning against more established analysis surrounding the politics of difference, are centred on the debate around recognition, redistribution, and representation (Dahl et al, 2004; Fraser, 2001; Walters, 2017). Fraser's work is an attempt to explain the impasse in progressive politics between traditionalists who draw on egalitarian, labour and socialist frameworks to seek equitable distribution of resources, goods and outcomes, and those who seek recognition of distinctive perspectives of ethnic, sexual minorities, and gender without the need to assimilate to dominant cultural norms (Fraser, 2001). The dissociation of struggles for recognition from those of redistribution is seen as a reflection of wider political decoupling, e.g. that of cultural politics from social difference, and the politics of difference from the politics of equality, or identity from status. Fraser wants to resist the displacement of redistribution by recognition or its framing as the sole category of normative reflection (Dahl et al, 2004), a position echoed by other leftist thinkers such as Rorty (2000).

CME, insofar as it frames difference in terms of social justice issues and equity, is a pedagogy aligned with the politics of redistribution. Recent, and at times trenchant, debate about the 'crisis' of liberalism and universities has suggested that identity for the current 
generation of students is no longer about group belonging (Goldstein, 2016), but the defence of the individual's social identity. In this context, traditional labels used in the critical understanding of difference are losing their salience in some educational contexts. For example, the number of students who consider themselves to be 'post-racial' is reported as a significant challenge to raising social justice issues in US sociology courses (Mueller, 2013). Educators (e.g. Gruenewald, 2003) in other subject areas have responded by seeking tactics by which to disassociate diversity from the individual. But whilst researchers acknowledge the importance of recognition politics and intersectionality for students (e.g. Grant and Zwier, 2011; McCall, 2005), it is not often present in our facilitation of management education or in our pedagogical discussions about criticality.

In this section, we have highlighted the challenges to critical management education's articulation in the classroom. The literature is clear about the poor fit between critical education practices and the higher education context it finds itself in (e.g. Clegg, Dany, and Grey 2012; Saren 2010; Solitander et al. 2012) and it is not difficult to establish the fault lines in the UK along which the tectonic plates of higher education policy and critical pedagogy meet each other. However, what is less obvious in the literature is how CME is responding to this changed context, and whether it sees a case for the re-examination of its practices and guiding concepts.

\section{Critical Management Education's Middle Age}

Now that CME is reaching middle-age in terms of practice, a more reflexive examination, one which addresses the emotions and politics of educational practice is overdue (Vince 2010). 
We note that there have been significantly fewer articles and books examining the continuing practice of CME than there have been charting its birth. In this section, we examine the work that has examined the roles, values and beliefs of management educators more recently.

The most relevant work recently has been that of Breen (2012). Breen's research identified that criticality is expressed differently according to the seniority and gender of the educators who identify as CME academics in Ireland and the UK. Senior male academics were more likely to report using critical content approaches, e.g. the use of critical theorists in lectures and readings, whereas the more junior women favoured process radical approaches e.g. the use of critical classroom methods. CME practitioners were also the subject of Fenwick's (2005) research, where she noted the tendency to occasionally act as 'zealous emancipatory educators (who) may bracket themselves out of their critique, establishing a new totalizing hegemony that simply reverses the knowledge hierarchy it presumes to interrupt' (2005: 33). Other papers have noted general signs of 'ageing' amongst the community - i.e. the tendency of critical educators to be critical from a safe distance in contrast with those who engage critically without using the label 'critical' (Clegg et al., 2006); the imbalance between critique and an ethic of care (Gabriel, 2009); a concern with acknowledging the complexities of management practices and contexts (Hay and Hodgkinson, 2008); and the lack of process challenge to contradictory behaviour within the wider critical community, especially when it gathers in conference mode (Bell and King, 2010).

The difficulty for CME, as a subset of CMS, as it encounters the new realities of higher education and the challenges to its traditional framing of power and difference, is that it 
continues to operate predominantly out of a Western, white and male academic tradition that has always found it difficult to acknowledge its own power, or to see how it shapes educational assumptions about the value of difference to the powerful. This was the basis of our previous criticism in (date) in this journal, and we note that whilst the radical education community - which provided the theoretical and interpretive base for CME process approaches - has debated these issues in the intervening period, there has not been evidence of the same robust debates taking place within CME.

The Debates Taking Place Elsewhere

The role of difference at the heart of group-based pedagogies, and educational practice around 'appreciating' difference, has been debated outside of management in fields such as sociology

and education. For example, based in sociological research on school volunteer programmes, Eliasoph (2001) notes that western, white male calls to acknowledge and appreciate diversity in group work and in the classroom more generally, is read by the already powerful i.e. white, affluent participants who are native English speakers (or the equally materially privileged from other cultures) as the need to appear tolerant, confident, and to mix and work with the difference of others in groups without hesitation. Similarly, when universities create so-called safe spaces where race and diversity can be discussed, they are often experienced by students from under-represented identity groups as timetabled opportunities for informing majority white, middle-class students about the 'other' (Leonardo and Porter, 2010). Too often it is this type of 'learning about difference' that is reproduced unproblematically in the published learning outcomes of mainstream and critical modules alike. 
CME has been slow to acknowledge that the greater the degree of relative privilege that an individual holds the greater the luxury they have of 'discovering' or 'learning about' difference in a classroom. Low power individuals enter the classroom already distracted by their ongoing experience of having to anticipate and manage the actions of the more powerful (Galinsky et al, cited in Bunderson and Reagans, 2010). Difference, of course, is further complicated by not being easy to distinguish from personal habits, idiosyncrasies or aspects of a culture, family identity and/or gender that the participant may wish to change, rather than celebrate (Eliasoph, 2011). This brings us back to the issue of identity politics. For example, as a woman, it is possible to want to assert some aspects of your gendered identity, whilst simultaneously feeling alienated from claims about your gendered identity that may be expressed by women in a different age-group, or who experience biological gender differently, or views popularised in the media as being shared by all women but with which you do not identify.

CME's silence over its own privileges, the changing nature of difference, and lack of challenge to masculinist norms embedded in content critical approaches is striking when contrasted with the debates within radical education. Yoon's (2005) critique of McLaren and Giroux et al, is an example of the feminist challenge within radical education that remains overdue in CMS and CME. Her challenge was wide-ranging, but core to her critique was the charge that setting up an idealised version of criticality allowed male theorists to shame educators who failed to live up to the authoritative, masculine figure of the transformative intellectual. There is a similar acknowledgement of the 'rather muscular idea(1)' of criticality 
and activism in Horton and Kraftl (2009: 17), that considers emotion in the classroom as either a straightforward prompt to, or tool for, action outside of it. Yoon (2005) also suggested that critical pedagogy constructed teachers as if they had been left uninscribed by specific narratives and contexts, even as they originate in so-called dominant cultures. This failure to confront these gendered and cultural undercurrents in critical pedagogy was, in the view of Yoon (2005), to allow them to continue to serve exclusionary and conservative ends.

In addition to the critique of the masculinist assumptions underpinning radical education, its researchers have also questioned the idea of an identifiable, consistent practice that could be identified as critical education. Ellsworth (2005) instead sees all educational practice and research as the ongoing project of articulating, negotiating, denying, fearing, ritualising, narrating the self-in-other and other-in-self. Criticality is just another single moment in the production and performance of multiple critical cultures and dislocations in practice. The idea of multiple dislocations has also been taken up by Mandiola Cotroneo (2013), who - like Ellsworth - believes that terms like 'criticality' are empty signifiers. Radical education, after the feminist challenge, became a concept and practice that was impossible to pin down, standardise, or collectively adapt (Yoon, 2005). The task of criticality became instead to use the experience of its impossibility to keep moving on and to learn from the failures, breaks, refusals and ruptures (Lather, 1998: 495; Yoon, 2005).

The likelihood of the modern university welcoming a series of failures, breaks, and ruptures in teaching performance, or the revelation of the same in student evaluations, is not tackled by these authors. But the overall sense of critical pedagogy as an unfolding, and somewhat 
restless, encounter with a changing set of impossibilities is now a key theme in the critical education literature outside of the business school. Newman (2012), for example, rejects the idea of critical learning being attributable to a single module. Dismissing most accounts of 'transformational' pedagogy as merely good practice, Newman points out that transformative learning at the individual level is the result of a slow, long and incremental process, or a profound emotional experience. Instead of trying to isolate critical, transformative education into specific teaching techniques or modules that self-identify as 'critical' there needs to be a greater emphasis on learning across space and time.

The cumulative message of the challenges within radical education over the last decade or so has been to question the dominant masculinist norms of 'right' action in relation to the politics of difference and redistribution, and criticality. Criticality, outside the boundaries of management education, has moved towards acknowledging the impossibility of considering criticality as an educational 'movement' and is more accepting of a fragmented and halting educational process within an institutional context that creates multiple tensions, or as a developmental arc that extends beyond the institutional period of influence. CME also needs to consider how its practices need to change. It is to this consideration of future practices that we turn in the final section of the paper.

\section{Criticality Revisited}

In a previous section of this paper, we noted the central concern of process CME practitioners with group work as a means of surfacing issues of difference. We also suggested that changes to the fee regime, internationalisation, risk aversion and challenges to traditional conceptions 
of difference were squeezing the space available for critical pedagogies. In this section, we examine three possible responses to the changed institutional and theoretical framing of criticality, two of which we acknowledge as reasonable individual responses and one which we advocate as a necessary step change in the collective CME response.

It is reasonable - given the challenges we have outlined to date in this paper - for an individual critical educator to choose to simply take advantage of whatever limited spaces still exist in the curriculum, and to wait for the tide in CME fortunes to turn again. For example, Sambrook and Willmott (2014), create discrete, modular, opportunities for critical work when it has been excluded from a programme as a whole - working incrementally where it is possible rather than attempting the impossibility of criticality at programme level. In similar vein, Fox (2012) is impatient with the idea that structural changes need to prevent educators from thinking through how to engage a new generation of students in critical conversation. More recently, Bell and Bridgman (2017), in an editorial for this journal, exhort their readers to continued 'engagement' as a response to the 'growing realisation of the potentially catastrophic effects of global environmental change and issues of democracy and inequality (which) are at the forefront of public discourse' (p. 4). However, an exhortation to simply keep calm and carry on with critical processes should not mean that we miss the opportunity to examine critical content. Nor does 'carrying on' challenge the continuing privilege of the educator in raising issues of difference, or the masculinist assumptions built into 'transformative' practices and tutor identity. 
A second possible response is to look for the opportunity for new critical pedagogies to arise from the widespread adoption of group work within management education, albeit dislocated from a wider programme of planned critical education (Ellsworth, 2005). It is now routine for students to study in groups on projects, business games, simulations, role-plays and a range of experiential activities both indoors and outdoors. The rationales vary. Some are based on pedagogical preference, some on expediency (more efficient use of teacher resource), some reflecting a belief in groups as 'motivating' or as a means of developing employability skills (Riebe et al, 2010). Most group work applications have mainstream management aims in respect of teaching key concepts and tools of task groups (e.g. Bull Schaefer and Erskine, 2012; Comer and Holbrook, 2012). However, few signal willingness to embrace the discomfort of learning from visible tensions of difference and power if and when they emerge, perhaps reflecting the 'unhelpful' but persistent myth that group work assumes equality, obviating the need to 'work on the impact of difference' (Vince, 1996: 127). Nevertheless, the ubiquity of group work, regardless of its rationale, might provide evolutionary opportunities for tutor/facilitators to invent new critical responses to tensions within group work that will take working with difference in as yet unknown directions. But if mainstream management education is to generate new critical responses to difference it will inevitably demand a broader range of knowledge and skill from the tutor. Vince's observations highlight the need for tutor reflexivity if mainstream group work is to engage with all types of politics of difference.

Our proposition, in contrast to the more limited options outlined above, is that the CME community should actively engage with the collective hard work of adapting to the structural 
changes and look for emergent alternatives to its current pedagogical designs. Given that it has no guaranteed place on the timetable, CME will need to consider a wider range of options for engaging students with issues of difference than it has had to previously. Although this position in itself assumes that it is critical management educators who get to set the agenda. (Recent student led protest movements such as \#Rhodesmustfall (Roux and Becker, 2017) and other examples of 'hashtag activism' are reminders that institutions are not always in control of their own framing of pedagogy).

Of course, we hope that difference, whether structural or as perceived, remains central to the identifiable collective concerns and practice of CME. Understanding difference is fundamental to CME for two reasons: firstly, difference remains central to our experience of work, life, and happiness. Mis-understanding or mis-recognising difference will probably account for most of the very awkward and painful learning experiences we have in life and being thoughtful about difference is core to thoughtful management practice in general. It is difficult to see a moral or educational case for not engaging with difference as part of the management curriculum. Difference, therefore, remains key to collectively re-evaluating the foundations of CME. However, whilst we want to argue for the continuing centrality of difference to $\mathrm{CME}$ we think there is more definitional work to be done in re-evaluating CME's position in relation to the politics of recognition and the politics of redistribution as outlined in the section above on identity politics, i.e. thinking about what sort of difference is relevant to students, as opposed to staff. 
What might the reconsideration of difference in critical management education result in? The choice each individual critical management educator makes in relation to where they place the emphasis of the political in relation to identity and difference is theirs alone - but the pedagogical designs that come out of those choices are likely to be very different. If the politics of recognition drove CME process it would appear to offer additional educational opportunities outside of the classroom, such as with visual arts praxis (Blume and Weatherston, 2017), or 'nomadic', self-organised, collaborative groups of students engaged in on-line learning (Ryberg, Davidsen and Hodgson, 2017), or other short term educational events that populate otherwise empty spaces in institutional life - the educational equivalent of 'pop up shops' (Niehm et al 2006; Mould 2014). A CME based on the politics of recognition would also look to those not currently studying in institutions but who wish to reengage with education and/or change their relationship to their past educational selves including alumni who desire to organise around their professional identities, or former students who identify with particular flagship programmes (J. Marshall, pers. comm, 23.10. 2017).

The politics of redistribution, as currently expressed through traditional process forms of CME, needs to do more work to confront the theoretical challenges it faces before it deals with its design issues. CME understandings of difference are rooted in very particular human rights literacies. Critics of current approaches to teaching about human rights and difference point out its uncritical and descriptive nature. Roux and Becker (2017), for example, point to the multiple ontological stances on differences and rights, and suggest that all have varying ethical, anthropological and epistemological consequences. These 'onto-epistemological' challenges are part of the landscape of engaging with difference in education settings and, in 
their view, will demand multi- and interdisciplinary collaborations and bottom-up teaching, learning and research approaches (Roux and Becker, 2017: 6). CME should find opportunities for such international (or cross national) and interdisciplinary collaborations with colleagues working in communication studies (see, for example, Allen and Ashcraft, 2009), continuing education, sociology, and arts and humanities scholars working with historical and literaturebased identity debates. Where CME currently involves participative methods, including group work, new differences will emerge as students and teachers negotiate context, methods and structures together. These negotiations will, of course, necessitate informed facilitation. ${ }^{4}$

Change is necessary. As a group we need to confront the theoretical and positional privileges that CME imported from radical education but has never completely interrogated - instructor privilege, 'muscular' notions of criticality, the persistent troublesome identity of the male, transformative critical educator. Some aspects of CME - like masculinist behaviour in academic settings - is already on the radar of groups such as VIDA - the critical management studies network of academics that identify as other than cis men. Activist networks are able to mobilise social media campaigns, petition sharing, and conference manifestos that help raise awareness. Community (re)formation seems key to progressing these important conversations about how CME both confronts and connects. The return of the 'Connecting Learning and Critique' conference ${ }^{5}$ would be a welcome first step. It previously acted as an important focus and forum for discussing criticality in management education in ways that the larger Critical Management Studies conference failed to do. In publications, or special issues, we need CME scholars to explore internationalization and criticality, identity politics and criticality, and the ways in which criticality is changed by the politics of recognition. If we do 
that work, rather than sit wait and wait for the context to change, then we will be welcomed into dialogue with students who see difference - and working with it - as an important part of their developmental arc, and longer story of critical development. As a first step we must address the structural problems in CME's current practice in order to bring new endeavours in criticality into existence.

\section{Conclusion}

Our concern in this paper has been to examine where CME finds itself now, specifically in terms of its response around group work and difference in the changed structural realities in UK education. There have been many changes in higher education since 2000, and particularly in management education. Increased marketization, coupled with internationalization of the student body - most noticeably at taught postgraduate level - have led to a more homogenous degree programme offering, with many smaller, post-experience programmes that were based on or related to critical pedagogy being squeezed out of the sector (Gross and Hogler 2005; Sambrook and Willmott, 2014; Tosey and Marshall, 2017). Whilst there is evidence that the CME community is all too aware of the changing external political and educational environment, there are few papers that specifically tackle CME in its middle age or that problematize its underpinning theoretical assumptions in relation to difference and/or the role of the critical educator given other changes around it.

At the conclusion of the paper we outlined the broad scope of work we think the critical management education community needs to do. CME is overdue for a reflexive consideration 
of the role of the critical educator, the privilege we claim when we introduce difference as learning, and the allure of the role of the transformative intellectual. Tackling these issues will entail difficult encounters with our own recognition and redistribution assumptions that is the basis of our current practice as teachers and researchers. We need to also question the easy assumption that any critical space we create is a 'clean' or 'safe' space for discussion and encounter (Eliasoph, 2011) whilst ignoring the permeable boundaries to the exterior world and its inequalities. Critical education may, as Yoon (2005) suggests, be impossible but it is the impossibility of critical pedagogy that creates the forward momentum as we try and move through one stuck moment after another.

\section{Acknowledgements}

The authors would particularly like to thank Professor Russ Vince for his supportive critique of earlier drafts, and the editor and reviewers for suggestions which have helped shape the final version.

\section{References}

Alvesson, M and Willmott, H. (Eds.) (1992) Critical Management Studies, London: Sage.

Baptiste, I. (2001). Educating lone wolves: Pedagogical implications of human capital theory'. Adult Education Quarterly 51(3): 184-201.

Bell, E. and Bridgman, T. (2017) (Editorial) Why management learning matters. Management Learning 48(1): 3-6.

Bell, E. and King, D. (2010) The elephant in the room: Critical management studies conferences as a site of body pedagogics. Management Learning. 41(4): 429-442. 
Blume, L. and Weatherston, R. (2017). Queering the campus gender landscape through visual arts praxis'. In E. McNeil, J. Wermers, and J. Lunn (eds) Mapping Queer Space (s) of Praxis and Pedagogy. Cham: Springer.

Breen, J. (2012). Exploring criticality in management education: To be critical or not to be critical that is the question.' Unpublished PhD Thesis, University of Sheffield.

Bridgman, T. (2007) Reconstituting relevance: Exploring possibilities for management educators' critical engagement with the public. Management Learning 38(4): 425-439.

Bull Schaefer, R. and Erskine, L. (2012). Virtual team meetings: Reflections on a class exercise exploring technology choice. Journal of Management Education, 36(6): 777801.

Bunderson, J. and Reagans, R. (2010). Structure and learning in self-managed teams: Why 'bureaucratic' teams can be better learners. Organization Science, 21(3): 609-624.

Choo, K. L. (2007). The implications of introducing critical management education to Chinese students studying in UK business schools: Some empirical evidence. Journal of Further and Higher Education 31(2): 145-158.

Clegg, S. R., Kornberger, M., Carter, C. and Rhodes, C. (2006) For management? Management Learning 37(1): 7-27.

Clegg, S., Dany, F. and Grey, C. (2012). Introduction to the special issue critical management studies and managerial education: New contexts? New agenda? Management 14(5): $272-279$.

Comer, D. R., and R. L. Holbrook. (2012). Getting behind the scenes of Fleetwood Mac's rumours: Using a documentary on the making of a music album to learn about task groups. Journal of Management Education 36(4): 544-567. 
Crawford, I. and Wang, Z., (2015). The impact of individual factors on the academic attainment of Chinese and UK students in higher education. Studies in Higher Education, 40(5): 902-920.

Crose, B., (2011). Internationalization of the higher education classroom: Strategies to facilitate intercultural learning and academic success. International Journal of Teaching and Learning in Higher Education, 23(3): 388-395.

Currie, G. (2007). Beyond our imagination: The voice of international students on the MBA. Management Learning 38(5): 539-556.

Dahl, H., Stoltz, P. and Willig, R. (2004) Recognition, redistribution and representation in capitalist global society: An interview with Nancy Fraser. Acta Sociologica, 47(4): 374-382.

Dehler, G. E., Welsh, M. A. and Lewis, M. W. (2001) Critical pedagogy in the 'New Paradigm‘. Management Learning 32(4): 493-511.

Eliasoph, N., (2011). Making Volunteers: Civic Life after Welfare's End. Princeton University Press.

Ellsworth, E. (1989) Why doesn't this feel empowering? Working through the repressive myths of critical pedagogy. Harvard Educational Review 59(3): 297-324.

Ellsworth, E. (2005). Multiculture in the making. In C.A Grant (ed.) Multicultural Research: a Reflective Engagement with Race, Class, Gender and Sexual Orientation. London: Routledge.

Fenwick, T. (2005) Ethical dilemmas of critical management education: Within classrooms and beyond. Management Learning 36(1): 31-48.

Fox, H. (2012). Their Highest Vocation: Social Justice and the Millennial Generation. New 
York: Peter Lang.

Fox, S., and Grey, C. (2000). Introduction: Connecting learning and critique. Management Learning, 31(1): 7-10.

Fraser, N. (2001). Recognition without ethics? Theory, Culture and Society, 18(2-3): 21-42.

Fuller, S. (2017) Brexit as the unlikely leading edge of the anti-expert revolution European Management Journal, http://dx.doi.org/10.1016/j.emj.2017.09.002.

Gabriel, Y. (2009) Reconciling an ethic of care with critical management pedagogy. Management Learning. 40(4): 379-385.

Gabriel, Y., and D. S. Griffiths. (2008). International learning groups: Synergies and dysfunctions. Management Learning 39(5): 503-518.

Giroux, H.A. (1981) Ideology, Culture, and the Process of Schooling. Philadelphia: Temple University Press.

Giroux, H. A. (1983) Theory and Resistance in Education, London: Heinemann.

Giroux, H. A. (1988) Teachers as Intellectuals: Towards a Pedagogy of Learning. New York: Bergin and Garvey.

Goldstein, E (2016) Campus identity politics is dooming liberal causes, a professor charges, Chronicle of Higher Education, December 15, 2016 [Online: http://www.chronicle.com/article/Campus-Identity-Politics-Is/238694]. $\quad$ Last Accessed: 15/12/16

Grant, C.A. and Zwier, E., (2011). Intersectionality and student outcomes: Sharpening the struggle against racism, sexism, classism, ableism, heterosexism, nationalism, and linguistic, religious, and geographical discrimination in teaching and learning. Multicultural Perspectives, 13(4): 181-188. 
Gross, M. A., and R. Hogler. (2005). What the shadow knows: Exploring the hidden dimensions of the consumer metaphor in management education. Journal of Management Education, 29(1): 3-16.

Gruenewald, D.A., (2003). The best of both worlds: A critical pedagogy of place. Educational researcher, 32(4): 3-12.

Gustavs, J. and Clegg, S. (2005) Working the knowledge game? Universities and corporate organizations in partnership. Management Learning 36(1): 9-30.

Hay, A. and Hodgkinson, M. (2008) More success than meets the eye - a challenge to critiques of the MBA: Possibilities for critical management education? Management Learning. 39(1): 21-40.

Horton, J. and Kraftl, P. (2009). Small acts, kind words and 'Not Too Much Fuss': Implicit activisms. Emotion, Space and Society, 2(1): 14-23.

Grey, C., Knights, D. and Willmott, H. (1996) Is a critical pedagogy of management possible? In R. French and C. Grey (Eds), Rethinking Management Education. London: Sage.

Lather, P. (1998). Critical pedagogy and its complicities: A praxis of stuck places. Educational Theory, 48(4): 487-497.

Leonardo, Z. and Porter, R. (2010) Pedagogy of fear: Toward a Fanonian theory of 'safety' in race dialogue. Race Ethnicity and Education, 13(2): 139-157.

Luke, C. and Gore, J. (Eds) (1992) Feminisms and Critical Pedagogy. London: Routledge.

Mandiola Cotroneo, M., (2013). Management education in Chile: From politics of pragmatism to (im) possibilities of resistance. Universitas Psychologica, 12(4): 10871100. 
Mangan, A., Kelemen, M. and Moffat, S., (2016). Animating the classroom: Pedagogical responses to internationalisation. Management Learning, 47(3): 285-304.

Mazzarol, T. and Soutar, G. N. (2012), Revisiting the global market for higher education, Asia Pacific Journal of Marketing and Logistics, 24(5): 717 - 737.

McCall, L. (2005). The complexity of intersectionality. Signs: Journal of Women in Culture and Society, 30(3): 1771-1800.

Mould, O. (2014), Tactical urbanism: The new vernacular of the creative city. Geography Compass, 8: 529-539.

Mowles, C. (2017) Experiencing uncertainty: On the potential of groups and a group analytic approach for making management education more critical. Management Learning, 48(5): $505-519$.

Mueller, J. C. (2013). Tracing family, teaching race: Critical race pedagogy in the millennial sociology classroom. Teaching Sociology, 41(2): 172-187.

Nafukho, F. M., Hairston, N. and Brooks, K. (2004). Human capital theory: Implications for human resource development. Human Resource Development International, 7(4): $545-551$.

Naidoo, R., and Jamieson, I. (2005). Empowering participants or corroding learning? Towards a research agenda on the impact of student consumerism in higher education. Journal of Education Policy, 20(3): 267-281.

Newman, M., (2012). Calling transformative learning into question: Some mutinous thoughts. Adult education quarterly, 62(1): 36-55.

Newson, J. A. (2004). Disrupting the 'student as consumer' model: The new emancipatory project. International Relations, 18(2): 227-239. 
Niehm, L., Fiore, A., Jeong, M. and Kim, H-J. (2006) Pop-up retail's acceptability as an innovative business strategy and enhancer of the consumer shopping experience, Journal of Shopping Center Research, 13(2): 1-30.

Perriton, L. (2007) Really useful knowledge? Critical management education in the UK and the US. Scandinavian Journal of Management. 23(1): 66-83.

Perriton, L. and Elliott, C. (2017) Equality. Diversity. Invisibility? A survey of the undergraduate management curriculum, Presentation to British Academy of Management Conference, September $2^{\text {nd }}$ 2017, University of Warwick.

Perriton, L. and Reynolds, M. (2004) Critical management education: From pedagogy of possibility to pedagogy of refusal? Management Learning, 35(1): 61-77.

Ployhart, R. E. and Moliterno, T. P. (2011). Emergence of the human capital resource: A multilevel model. Academy of Management Review, 36(1): 127-150.

Reynolds, M. and Trehan, K. (2003) Learning from difference? Management Learning, 34(2): 163-180.

Reynolds, M. and Vince, R. (2004) Critical management education and action-based learning: Synergies and contradictions. Academy of Management Learning and Education. 3(4): $442-56$.

Riebe, L., Roepen, D., Santarelli, B. and Marchioro, G., (2010). Teamwork: Effectively teaching an employability skill'. Education+ Training, 52(6/7): 528-539.

Rorty, R., (2000). Is 'cultural recognition' a useful concept for leftist politics? Critical Horizons, 1(1): 7-20.

Roux, C. and Becker, A. (2017) On critique, dissensus and human rights literacies. South African Journal of Higher Education, 31(6): 1-8. 
Ryberg, T., Davidsen, J. and Hodgson, V. (2017) Understanding nomadic collaborative learning groups. British Journal of Educational Technology. [Early View Online] doi:10.1111/bjet.12584

Sambrook, S. and Willmott, H. (2014) The rigor of management education and the relevance of human resource development: Natural partners or uneasy bedfellows in management practice? Management Learning, 45(1): 39-56.

Saren, M. (2010). Provocation: business schools and economic crisis - we are all critical now: But critique of what, for whom? International Journal of Management Concepts and Philosophy, 4 (1): 28-33.

Sinclair, A. (1997) The MBA through women's eyes: Learning and pedagogy in management education. Management Learning 28(3): 313-330.

Sinclair, A. (2007) Teaching leadership critically to MBAs: Experiences from heaven and hell. Management Learning, 38(4): 458-472.

Solitander, N., Fougère, M., Sobczak, A. and Herlin, H. (2012). We are the champions: organizational learning and change for responsible management education. Journal of Management Education, 36(3): 337-363.

Starkey, K., and N. Tiratsoo. (2007). The Business School and the Bottom Line. Cambridge: Cambridge University Press.

Tosey, P. and Marshall, J. (2017) The demise of inquiry-based HRD programmes in the UK: Implications for the field. Human Resource Development International 20(5): 393402. 
Turner, Y. (2009). 'Knowing me, knowing you,' is there nothing we can do? Pedagogic challenges in using group work to create an intercultural learning space. Journal of Studies in International Education, 13(2): 240-255.

Vince, R. (1996) Experiential management education as the practice of change. In R. French and C. Grey, (Eds), Rethinking Management Education. London: Sage.

Vince, R. (2010) Anxiety, politics and critical management education. British Journal of Management, 21(S1): sS26-s39.

Walters, S (2017) In defence of identity politics. Signs: Journal of Women in Culture and Society, [Online] http://signsjournal.org/currents-identity-politics/walters/ [Last access $4 / 12 / 17]$

Whittier, N. (2017) Identity politics, consciousness-raising, and visibility politics, in H. McCammon, V. Taylor, J. Reger and R. Einwohner (eds), The Oxford Handbook of US Women's Social Movement Activism, Oxford University Press: New York.

Wilkins, S. and Huisman, J., (2012) UK business school rankings over the last 30 years (1980-2010): Trends and explanations. Higher Education, 63(3): 367-382.

Yoon, K.H. (2005). Affecting the transformative intellectual: Questioning 'noble' sentiments in critical pedagogy and composition. JAC: A Journal of Rhetoric, Culture, and Politics, 25(4): 717-759.

\footnotetext{
${ }^{1}$ We acknowledge this concern is situated in the strand of CME that is allied with a process radical approach. CME, as a wider field, also identifies modules and programmes with radical content as critical (Perriton, 2007).

${ }^{2}$ We use 'group work' to refer to critical pedagogies which while different in some respects are likely to involve students in working in groups, thus providing opportunities to learn about power and difference, both central to CME.

${ }^{3}$ After 1987 undergraduate students were charged $£ 1,050$ a year towards the average cost of $£ 5,000$ of providing their education. The remainder was paid by government to universities directly. In 2006 so called 'top up' fees of $£ 3,000$ were introduced to bring the student contribution closer to the 'real' cost of their education. In 2012, top up fees were replaced with variable fees of up to $£ 9000$ per year, which instead of being payable up-front (as was the case with top up fees) would be provided as a loan, repayable after graduation when the graduate reached a certain level of income.
} 
${ }^{4}$ As an example of this position, see Mowles, (2017) for a detailed account of how psychodynamic perspectives can provide a basis for criticality in management learning groups.

${ }^{5}$ See Fox and Grey (2000). The conference ran bi-annually from 1998 to 2002. 